\title{
A short review of primary aldosteronism in a question and answer fashion
}

\author{
Frederick-Anthony Farrugia ${ }^{1}$, Nicolaos Zavras ${ }^{2}$, Georgios Martikos ${ }^{3}$, Panagiotis Tzanetis ${ }^{3}$, \\ Anestis Charala mpopoulos ${ }^{4}$, Evangelos P. Misiakos ${ }^{4}$, Dimitrios Sotiropoulos ${ }^{5}$, Nikolaos Koliakos ${ }^{5}$ \\ ${ }^{1}$ General Surgeon, Private practice, Athens, Greece; ${ }^{2}$ Associate Professor of Pediatric Surgery, Department of Pediatric \\ Surgery, Attikon University Hospital, University of Athens School of Medicine, Athens, Greece; ${ }^{3}$ Consultant Surgeon, \\ $3^{\text {rd }}$ Department of Surgery, Attikon University Hospital, University of Athens School of Medicine, Athens, Greece; \\ ${ }^{4}$ Associate Professor Surgery, $3^{\text {rd }}$ Department of Surgery, Attikon University Hospital, University of Athens School of \\ Medicine, Athens, Greece; ${ }^{5}$ Resident Surgeon, $3^{\text {rd }}$ Department of Surgery, Attikon University Hospital, University of \\ Athens School of Medicine, Athens, Greece \\ E-mail:farrugiafa@gmail.com
}

Objectives. The aim of this study was to present up to date information concerning the diagnosis and treatment of primary aldosteronism (PA). PA is the most common cause of endocrine hypertension. It has been reported up to $24 \%$ of selective referred hypertensive patients.

Methods. We did a search in Pub-Med and Google Scholar using the terms: PA, hyperaldosteronism, idiopathic adrenal hyperplasia, diagnosis of PA, mineralocorticoid receptor antagonists, adrenalectomy, and surgery. We also did cross-referencing search with the above terms. We had divided our study into five sections: Introduction, Diagnosis, Genetics, Treatment, and Conclusions. We present our results in a question and answer fashion in order to make reading more interesting.

Results. PA should be searched in all high-risk populations. The gold standard for diagnosis $\mathrm{PA}$ is the plasma aldosterone/plasma renin ratio (ARR). If this test is positive, then we proceed with one of the four confirmatory tests. If positive, then we proceed with a localizing technique like adrenal vein sampling (AVS) and CT scan. If the lesion is unilateral, after proper preoperative preparation, we proceed, in adrenalectomy. If the lesion is bilateral or the patient refuses or is not fit for surgery, we treat them with mineralocorticoid receptor antagonists, usually spironolactone.

Conclusions. Primary aldosteronism is the most common and a treatable case of secondary hypertension. Only patients with unilateral adrenal diseases are eligible for surgery, while patients with bilateral and non-surgically correctable PA are usually treated by mineralocorticoid receptor antagonist (MRA). Thus, the distinction between unilateral and bilateral aldosterone hypersecretion is crucial.

Key words: primary aldosteronism, aldosterone producing adenoma, idiopathic adrenal hyperplasia, diagnosis, radiology, treatment, surgery

\section{What is the history and definition of primary aldosteronism (PA)?}

Despite the fact that PA caused by aldosterone producing adenoma (APA) is called Conn's Syndrome, it was actually, first described by
Litynski in Poland in 1953 (Kucharz 2007) and later by Conn in USA in 1955 (Conn 1955). Conn described it in a patient presenting with resistant hypertension (HTN) and hypokalemia who was found to have an aldosterone-secreting adrenal adenoma (Conn 1955). PA is a group of disorders, 
in which aldosterone production is inappropriately high, relatively autonomous from the renin-angiotensin system, and non-suppressible by sodium loading. Such inappropriate production of aldosterone causes cardiovascular damage, suppression of plasma renin, hypertension, sodium retention, and potassium excretion that if prolonged and severe may lead to hypokalemia (Funder et al. 2008).

\section{What is the pathology of PA?}

PA is commonly caused by an adrenal adenoma, by unilateral or bilateral adrenal hyperplasia or in rare cases by the inherited condition of familial hyperaldosteronism (Funder et al. 2008). Hyperaldosteronism may be caused by aldosterone-producing carcinomas (Brunt and Moley 2001). A detailed list of all causes of PA follows:

1. Bilateral idiopathic hyperplasia (BIH) $60 \%$ of cases. (This is also referred and as idiopathic hyperaldosteronism (IHA).

2. Aldosterone-producing adenoma (APA) (or Conn's syndrome) in $35 \%$ of cases.

3. Primary (Unilateral) adrenal hyperplasia $2 \%$ of cases.

4. Aldosterone-producing adrenocortical carcinoma $<1 \%$ of cases.

5. Familial hyperaldosteronism (FH).

a. Glucocorticoid-remediable aldosteronism (GRA) or (FH type I) $<1 \%$ of cases.

b. FH type II (APA or BIH) $<2 \%$ of cases.

6. Ectopic aldosterone producing adenoma or carcinoma $<0.1 \%$ of cases (Kahn and Angle 2010; Moraitis and Stratakis 2011).

Geller et al. (2008) discovered a novel form of Mendelian HTN caused by massive adrenal mineralocorticoid production in a family of treatment resistant hypertensive, a father and two daughters. This was named FH III. The molecular basis of FH-III was identified as a germline mutation (p.T158A) in the KCNJ5 gene encoding the G-protein-activated inward rectifier K channel 4 (Monticone et al. 2013). The true incidence of FH III is not yet known.

\section{Physiology of aldosterone}

Aldosterone, produced in the adrenals' zona glomerulosa, is synthesized and released mainly in response to renin-dependent production of angiotensin II; however, adreno-corticotropic-hormone $(\mathrm{ACTH})$, serum potassium, and dopamine also affect its production and secretion (Mattsson and Young 2006). In epithelial tissues (e.g. renal tubular cells, distal colon and salivary glands) aldosterone enhances uptake of sodium; water follows, resulting in increased volume load and cardiac output. Sodium reabsorption is accompanied by potassium excretion (Mattsson and Young 2006). Aldosterone induces oxidative stress, endothelial dysfunction, inflammation and fibrosis in the vasculature, heart and kidney (Brown 2005). Studies in animal models and in patients with congestive heart failure or hypertension indicate that aldosterone induces oxidative stress and impairs endothelial nitric oxide synthase through a mineralocorticoid receptor-dependent mechanism. Furthermore, aldosterone can cause vasoconstriction and vasodilation through rapid nongenomic mechanisms (Brown 2005). Hypertension results partly from an increase in plasma volume and partly from the aldosterone-mediated vasoconstriction of systemic arteries (McCurley et al. 2012; Steichen et al. 2015).

\section{What is the epidemiology of PA?}

Increasing evidence indicates that $\mathrm{PA}$ is much more prevalent than previously believed, making this disease the most frequent cause of secondary hypertension (Mulatero et al. 2002). The reported prevalence may depend in part upon the population that is screened (Kline 2015). Various studies report PA in more than $10 \%$ of hypertensive patients, both in general and special settings (Gordon et al. 1994; Fardella et al. 2000; Funder et al. 2008). Populations of patients with "resistant hypertension" may have PA prevalence of 10-24\% (Fardella et al. 2000), compared to rates of $1-13 \%$ in less selected hypertension populations (Hood et al. 2005; Schwartz and Turner 2005; Kline 2015).

\section{What are the signs and symptoms of PA?}

It often produces few symptoms (Schirpenbach and Reincke 2007). Most people have high blood pressure, which may cause poor vision or headaches (Schirpenbach and Reincke 2007; AAES 2016). The most common symptoms are headaches, vision problems, fatigue, muscle cramps, muscle weakness, numbness, temporary paralysis, increased urine, and increased thirst (AAES 2016).

\section{What is the morbidity and mortality of PA?}

This condition is important not only because of its prevalence but also because PA patients have higher cardiovascular morbidity and mortality than age and sex-matched patients with essential hypertension and the same degree of blood pressure elevation (Milliez 
et al. 2005; Stowasser et al. 2005; Funder et al. 2008). Untreated PA is known to be associated with higher rates of cardiac arrhythmia, coronary heart disease, heart failure, stroke, proteinuria, and renal impairment compared to essential hypertension (Rossi et al. 2006a; Reincke et al. 2009; Mulatero et al. 2013; Kline 2015). Patients with PA had a higher rate of 24-h urine albumin excretion despite a normal glomerular filtration rate (GFR), compared to those with essential hypertension (Rossi et al. 2006b). It has also been reported that PA patients have worse quality of life (Ahmed et al. 2011).

\section{DIAGNOSIS}

\section{Who is eligible for PA screening?}

Until relatively recently, screening was limited to evaluating patients who had a combination of resistant hypertension and hypokalemia and involved only evaluation of the plasma aldosterone (PAC) (Weiner 2013).

According to the Endocrine Society's "Clinical Practice Guideline", it is recommended to search for primary aldosteronism (PA) in patient groups with relatively high prevalence of PA. These include patients with Joint National Commission stage 2 (BP >160-179/100-109 $\mathrm{mmHg}$ ), stage 3 (BP $>180 / 110 \mathrm{mmHg}$ ), or drug-resistant hypertension; hypertension and spontaneous or diuretic-induced hypokalemia; hypertension with adrenal incidentaloma; or hypertension and a family history of earlyonset hypertension or cerebrovascular accident at a young age ( $<40$ years). It is also recommended case detection for all hypertensive first-degree relatives of patients with PA (Funder et al. 2008).

\section{What is the most important test for diagnosing PA?}

The gold standard for PA diagnosis is the use of ARR to detect cases of PA in these patient groups (Funder et al. 2008; Aronova et al. 2014a). Numerous studies have demonstrated the ARR to be superior to measurement of potassium or aldosterone (both of which have lower sensitivity) or renin (which is less specific) in isolation (Hiramatsu et al. 1981; McKenna et al. 1991; Stowasser et al. 2003; Funder et al. 2008). There are important and confusing differences between laboratories in the methods and units used to report values of renin and aldosterone (Funder et al. 2008).

As with all the biochemical tests, ARR has false positive and negative tests (Schwartz and Turner 2005; Rossi et al. 2006a; Funder et al. 2008), the ARR should therefore be regarded as a detection test only and should be repeated if the initial results are inconclusive or difficult to interpret because of suboptimal sampling conditions (Funder et al. 2008). ARR ratio $\geq 20 \mathrm{ng} / \mathrm{dl}$ per $\mathrm{ng} / \mathrm{ml}$ per hour (554 $\mathrm{pmol} / \mathrm{l}$ per $\mathrm{ng} / \mathrm{ml}$ per hour) in combination with a plasma aldosterone concentration (PAC) $\geq 15 \mathrm{ng} / \mathrm{dl}(416 \mathrm{pmol} / \mathrm{l})$ in a morning blood sample from an ambulant patient is indicative of primary aldosteronism (Mattsson and Young 2006).

\section{What are the pitfalls of ARR and how to correct them?}

Aldosterone's levels are influenced by certain drugs (Mulatero et al. 2002). In a study by Mulatero et al. (2002) on "Drug Effects on Aldosterone/Plasma Renin Activity Ratio in Primary Aldosteronism”, they found that some drugs may change the ARR up to $62 \%( \pm 82)$ as in the case of atenolol.

This can be corrected by stopping these medications (Mulatero et al. 2002) and replacing them by medications that do not interfere with aldosterone levels (Funder et al. 2008). Ideal testing conditions involve discontinuation of such medications two weeks prior (Tomaschitz and Pilz 2010; Stowasser et al. 2012; Chao et al. 2013). In the Table 1, there is a list of the medications and other conditions that interfere with aldosterone levels and in Table 2 there is a list with the medications that can replace them. Gender, contraceptives, and use of antidepressants also can affect the ARR (Fischer et al. 2013).

\section{How frequent is hypokalemia in PA?}

Normokalemic hypertension constitutes the most common presentation of the disease (Young 2002; Mulatero et al. 2004; Schirpenbach et al. 2006; Funder et al. 2008), with hypokalemia probably present in only the more severe cases (Funder et al. 2008). Half of the patients with an APA and $17 \%$ of those with idiopathic hyperaldosteronism (IHA) had serum potassium concentrations less than $3.5 \mathrm{mmol} / 1$ (Rossi et al. 2006a,b; Funder et al. 2008). Thus, the presence of hypokalemia has low sensitivity and specificity and a low positive predictive value for the diagnosis of PA (Funder et al. 2008).

\section{After positive ARR, do we proceed to subtype PA or we go on with confirmatory tests? What are we doing next?}

It is recommended that instead of proceeding directly to subtype classification, that patients with a positive ARR undergo testing, by any of four confir- 
matory tests, to definitively confirm or exclude the diagnosis (Funder et al. 2008).

\section{Which are the 4 confirmatory tests?}

The current literature does not identify a gold standard confirmatory test for PA (Funder et al. 2008). The four confirmatory tests are: oral sodium loading, saline infusion test (SIT), fludrocortisone suppression test (FST), and captopril challenge (Funder et al. 2008).

\section{How is sodium loading performed and interpreted?}

Patients should increase their sodium intake to $>200 \mathrm{mmol} / \mathrm{d}(\approx 6 \mathrm{~g} / \mathrm{d})$ for 3 days, verified by $24-\mathrm{h}$ urine sodium content. Patients should receive adequate slow-release potassium chloride supplementation to maintain plasma potassium in the normal

Table 1

List of medications and other conditions that influence aldosterone levels

\begin{tabular}{|c|c|c|}
\hline \multirow{11}{*}{ A } & \multirow{11}{*}{ Medications } & 1) $\beta$-Adrenergic blockers \\
\hline & & $\begin{array}{l}\text { 2) Central } \alpha-2 \text { agonists (e.g. clonidine } \\
\text { and } \alpha \text {-methyldopa) }\end{array}$ \\
\hline & & 3) NSAIDs \\
\hline & & 4) $\mathrm{K}+$-wasting diuretics \\
\hline & & 5) $\mathrm{K}+$-sparing diuretics \\
\hline & & 6) ACE inhibitors \\
\hline & & $\begin{array}{l}\text { 7) Angiotensin II type } 1 \text { receptor } \\
\text { blocker (ARBs) }\end{array}$ \\
\hline & & 8) Ca2-blockers (DHPs) \\
\hline & & 9) Renin inhibitors \\
\hline & & 10) Contraceptives \\
\hline & & 11) Antidepressants \\
\hline \multirow{2}{*}{ B } & \multirow{2}{*}{$\begin{array}{l}\text { Potassium } \\
\text { Status }\end{array}$} & 1) Hypokalemia \\
\hline & & 2) Potassium loading \\
\hline \multirow[b]{2}{*}{ C } & \multirow{2}{*}{ Dietary Sodium } & 1) Sodium restricted \\
\hline & & 2) Sodium loaded \\
\hline \multirow{7}{*}{ D } & \multirow{7}{*}{$\begin{array}{l}\text { Other } \\
\text { Conditions }\end{array}$} & 1) Advancing age \\
\hline & & 2) Renal impairment \\
\hline & & $\begin{array}{l}\text { 3) Pseudohypoaldosteronism } \\
\text { type } 2 \text { (familial hypertension and } \\
\text { hyperkalemia with normal glomerular } \\
\text { filtration rate) (PHA-2) }\end{array}$ \\
\hline & & 4) Pregnancy \\
\hline & & 5) Renovascular HT \\
\hline & & 6) Malignant HT \\
\hline & & 7) Gender (male) \\
\hline
\end{tabular}

range. Urinary aldosterone is measured in the $24-\mathrm{h}$ urine collection from the morning of day 3 to the morning of day 4 (Funder et al. 2008). PA is unlikely if urinary aldosterone is lower than $10 \mu \mathrm{g} / 24 \mathrm{~h}$ $(27.7 \mathrm{nmol} / \mathrm{d})$ in the absence of renal disease where PA may coexist with lower measured urinary aldosterone levels. Elevated urinary aldosterone excretion $[>12 \mu \mathrm{g} / 24 \mathrm{~h}(>33.3 \mathrm{nmol} / \mathrm{d})$ at the Mayo Clinic, $>14 \mu \mathrm{g} / 24 \mathrm{~h}(38.8 \mathrm{nmol} / \mathrm{d})$ at the Cleveland Clinic] makes PA highly likely (Funder et al. 2008).

\section{How is SIT performed and interpreted?}

Patients stay in the recumbent position for at least $1 \mathrm{~h}$ before and during the infusion of 2 liters of $0.9 \%$ saline iv over $4 \mathrm{~h}$, starting at 08:00-09:30 h. Blood samples for renin, aldosterone, cortisol, and plasma potassium are drawn at time zero and after $4 \mathrm{~h}$, with blood pressure and heart rate monitored throughout the test. Postinfusion plasma aldosterone levels $<5 \mathrm{ng} / \mathrm{dl}$ make the diagnosis of PA unlikely, and levels $>10 \mathrm{ng} / \mathrm{dl}$ are a very probable sign of PA. Values between 5 and $10 \mathrm{ng} / \mathrm{dl}$ are indeterminate (Kem et al. 1971; Giacchetti et al. 2006; Funder et al. 2008).

\section{What are the dangers of the two above tests?}

Sodium loading and saline infusion test should not be performed in patients with severe uncontrolled hypertension, renal insufficiency, cardiac insufficiency, cardiac arrhythmia, or severe hypokalemia (Funder et al. 2008).

\section{How is the FST performed?}

Patients receive $0.1 \mathrm{mg}$ oral fludrocortisone every $6 \mathrm{~h}$ for 4 days, together with slow-release $\mathrm{KCl}$ supplements (every $6 \mathrm{~h}$ at doses sufficient to keep plasma $\mathrm{K}+$, measured four times a day, close to $4.0 \mathrm{mmol} / \mathrm{l}$ ),

Table 2

Medications that can be used without interfering with aldosterone levels

\begin{tabular}{ll}
\hline Name of the drug & Dose \\
\hline Verapamil slow-release & $\begin{array}{l}90-120 \mathrm{mg} \text { twice daily } \\
10-12.5 \mathrm{mg} \text { twice daily, increasing } \\
\text { as required }\end{array}$ \\
Hydralazine & $\begin{array}{l}0.5-1 \mathrm{mg} \text { two to three times daily, } \\
\text { increasing as required }\end{array}$ \\
Prazosin HCL & $\begin{array}{l}1-2 \mathrm{mg} \text { once daily, increasing as } \\
\text { required }\end{array}$ \\
Doxazosin Mesylate & $\begin{array}{l}1-2 \text { mg once daily, increasing as } \\
\text { required }\end{array}$ \\
\hline Terazosin HCL & \\
\hline
\end{tabular}


slow-release $\mathrm{NaCl}$ supplements $(30 \mathrm{mmol} / \mathrm{l}$ three times daily with meals) and sufficient dietary salt to maintain a urinary sodium excretion rate of at least 3 $\mathrm{mmol} / \mathrm{kg}$ body weight. On day 4, plasma aldosterone and plasma renin activity are measured at 10:00 $\mathrm{h}$ with the patient in the seated posture, and plasma cortisol is measured at 07.00 and 10:00 h (Funder et al. 2008). The patients should receive gastroprotection either with a proton pump inhibitor once daily or with ranitidine $150 \mathrm{mg}$ twice daily. The drug used for gastroprotection should be started prior to fludrocortisone.

Upright plasma aldosterone $>6 \mathrm{ng} / \mathrm{dl}$ on day 4 at 10:00 h confirms PA, provided plasma renin activity (PRA) is $<1 \mathrm{ng} / \mathrm{ml}$ per hour and plasma cortisol concentration is lower than the value obtained at 07:00 h (to exclude a confounding ACTH effect) (Gordon 1994; Gordon et al. 1994; Gordon 1995; Gordon 2001; Stowasser et al. 2003; Stowasser and Gordon 2004; Funder et al. 2008).

\section{How is the captopril challenge performed and interpreted?}

Patients receive 25-50 mg captopril orally after sitting or standing for at least 1 hour. Blood samples are drawn for measurement of plasma renin activity (PRA), plasma aldosterone, and cortisol at time zero and at 1 or $2 \mathrm{~h}$ after challenge, with the patient remaining seated during this period (Funder et al. 2008). Plasma aldosterone is normally suppressed by captopril (>30\%). In patients with PA, it remains elevated and PRA remains suppressed. Differences may be seen between patients with APA and those with IHA, in that some decrease of aldosterone levels is occasionally seen in IHA (Mantero et al. 1981; Agharazii et al. 2001; Rossi et al. 2002; Rossi et al. 2007; Funder et al. 2008).

\section{What is adrenal vein sampling (AVS), when it is performed and when it may be excluded?}

AVS is the criterion standard to distinguish between unilateral and bilateral adrenal disease in patients with PA (Young and Stanson 2009). The use of AVS to distinguish between IHA and APA was first proposed by Melby et al. (1967). AVS should be performed only in patients with confirmed PA who want to pursue the surgical option in the management of their hypertension (Funder et al. 2008; Young and Stanson 2009).

For cases in which APA is highly likely (patients $\leq 40$ years of age with marked primary aldosteronism, e.g. PAC $\geq 30 \mathrm{ng} / \mathrm{dl}(832 \mathrm{pmol} / \mathrm{l})$ and a welldefined, hypodense adrenal mass ( $>1 \mathrm{~cm}$ on CT scan) is identified, AVS can be bypassed and the patient can undergo unilateral laparoscopic adrenalectomy (Young 2003a,b; Mattsson and Young 2006).

\section{How AVS is performed and interpreted?}

Adrenal vein sampling is a safe, highly effective procedure that is shown to alter the clinical management in $35.7 \%$ of PA patients who would have otherwise been treated improperly based on the results of CT or other modalities (Kahn and Angle 2010). Although adrenal vein sampling is hindered by the inherent difficulty of catheterizing the right adrenal vein, technical success is reported as high as $97 \%$ in experienced hands (Kahn and Angle 2010). The keys to successful AVS include appropriate patient selection, careful patient preparation, focused technical expertise, defined protocol, and accurate data interpretation (Young and Stanson 2009).

Aldosterone and cortisol concentrations are measured in the blood from all three sites (right adrenal vein, left adrenal vein, and inferior vena cava (IVC) (Young and Stanson 2009). The cortisol concentrations from the adrenal veins and IVC are used to confirm successful catheterization; the adrenal vein to IVC cortisol ratio is typically more than 10:1 with the continuous cosyntropin infusion protocol (Young et al. 2004; Young and Stanson 2009). When cosyntropin infusion is used, an adrenal vein to IVC cortisol gradient of at least 5:1 is required to be confident that the adrenal veins were successfully catheterized. This gradient is achieved in $96 \%$ of our patients (Young et al. 2004; Young and Stanson 2009). However, when cosyntropin infusion is not used, an adrenal vein to IVC cortisol gradient of more than 3:1 is recommended (Mengozzi et al. 2007; Young and Stanson 2009); although, others have suggested even lower cut-offs (Rossi et al. 2006c; Rossi et al. 2008; Young and Stanson 2009).

\section{Why is radiology and AVS important?}

Only patients with lateralized adrenal hypersecretion can be cured by unilateral adrenalectomy; hence, the distinction between unilateral and bilateral aldosterone hypersecretion is the key (Iacobone et al. 2015).

\section{GENETICS}

\section{Which are the genes responsible for PA?}

Over the last few years, the use of exome sequencing has significantly improved our understanding of 
this syndrome. Somatic mutations in the KCNJ5, ATP1A1, ATP2B3 or CACNA1D genes are present in more than half of all cases of aldosterone-producing adenoma ( $\sim 40 \%, \sim 6 \%, \sim 1 \%$ and $\sim 8 \%$, respectively). Germline gain-of-function mutations in KCNJ5 are now known to cause familial hyperaldosteronism type III, and an additional form of genetic hyperaldosteronism has been reported in patients with germline mutations in CACNA1D. These genes code for channels that control ion homeostasis across the plasma membrane of zona glomerulosa cells. Moreover, all these mutations modulate the same pathway, in which elevated intracellular calcium levels lead to aldosterone hyperproduction and (in some cases) adrenal cell proliferation (Al-Salameh et al. 2014). The molecular basis for FH-II is unclear, although several linkage analyses have shown an association with chromosomal region 7p22 (Lafferty et al. 2000; So et al. 2005; Funder et al. 2008). Finally, APA may rarely but on occasion be seen in multiple endocrine neoplasia type 1 (Funder et al. 2008).

\section{Who are eligible for genetic testing?}

In patients with onset of confirmed PA earlier than at 20 years of age and in those who have a family history of PA or of strokes at young age, it is suggested genetic testing for FH type 1 (GRA) (Funder et al. 2008).

\section{RADIOLOGY}

\section{What is the PA appearance on Ultrasound (U/S) and $\mathrm{CT}$ radiology?}

Ultrasound are of no help since hormoneproducing adrenal tumors, such as adenoma in Conn's syndrome, are generally too small to be detectable by U/S (Hofer 1999).

According to the "Clinical Practice Guidelines" of the Endocrine Society, it is recommended that all patients with PA undergo an adrenal CT scan as the initial study in subtype testing and to exclude large masses that may represent adrenocortical carcinoma (Funder et al. 2008).

Most aldosterone-producing adenomas are less than $20 \mathrm{~mm}$ in diameter (Letavernier et al. 2008; White et al. 2008). In a survey on adrenal incidentalomas in Italy, done by Mantero et al. (2000), they concluded that the majority of cortical adenomas were nonfunctioning $69 \%$, whereas $25 \%$ secreted cortisol in slight excess, and only $6 \%$ secreted aldosterone.

Density assessment following i.v. contrast administration is necessary in such cases. Moderate enhance- ment, followed by a rapid contrast agent washout from the tumor occurs in adenomas (Papierska et al. 2013). An absolute contrast washout of $>60 \%$ and a relative contrast washout of $>40 \%$ characterize an adenoma with a sensitivity and specificity of $98 \%$ and $92 \%$ respectively (Dunnick and Korobkin 2002; Szolar et al. 2005).

APA may be visualized as small hypodense nodules, usually $<2 \mathrm{~cm}$ in diameter on CT (Funder et al. 2008). It is mostly of a homogeneous structure (Ctvrtlik et al. 2014). In IHA adrenal glands may be normal on $\mathrm{CT}$ or show nodular changes. Aldosterone-producing adrenal carcinomas are almost always more than 4 $\mathrm{cm}$ in diameter, but occasionally smaller, and like most adrenocortical carcinomas have a suspicious imaging phenotype on CT (Young 2007; Funder et al. 2008). The adrenal CT lacks the overall accuracy to distinguish between unilateral and bilateral disease (Mattsson and Young 2006).

\section{What is the PA appearance on MRI radiology?}

On MRI, adenomas appear homogeneous on all sequences (Ilias et al. 2007). Their contrast enhancement is mild; they have low or equal signal intensity to the liver on T2-weighted images and may appear of lower signal intensity than the rest of the adrenal gland (Thompson and Young 2003; Ilias et al. 2007). MRI also makes use of the lipid content of adenoma. In-phase and out-of-phase imaging demonstrates a loss of signal in a lipid-rich adenoma, on the outof-phase image compared with the corresponding in-phase imaging. A metastatic deposit does not demonstrate this loss of signal (Conder et al. 2009).

\section{What is the PA appearance on scintigraphy or PET/CT radiology?}

Adrenal scintigraphy with 6ß-131Iodomethyl19-norcholesterol (NP-59), was introduced in 1977, currently, it is no longer used in most centers (Funder et al. 2008). Contrary to this Spyridonidis et al. (2013), in a study from Greece, they concluded that, "in previous years NP-59 scintigraphy was used infrequently, but recently with the advent of hybrid single photon emission tomography (SPET/CT) systems the interest in NP-59 scintigraphy has been renewed. Studies comparing NP-59 SPET/CT imaging with AVS are warranted in order to establish its diagnostic accuracy".

On a PET/CT scan, most commonly using 18F-fluorode oxyglucose (18F FDG PET/CT), the vast majority of adenomas do not accumulate the radiopharmaceutical. According to meta-analyses, 18F FDG PET/CT 
scanning generally has a high sensitivity (97\%) and specificity (91\%) in distinguishing between a malignant and benign adrenal lesion (Boland et al. 2011; Ctvrtlik et al. 2014). In a recent study by Powlson et al. (2015), they used the metomidate, as a potent ligand of CYP11B1 and CYP11B2, which can be C11H3-labelled as a PET tracer. They concluded that "increasing experience with 11C-metomidate PET-CT supports its use as an adjunct to AVS when this has failed, is ambiguous, or cannot be undertaken". The same was confirmed by other studies (Bergstrom et al. 2000; Burton et al. 2012; Brown 2015).

\section{What is Aldosteronoma Resolution Score (ARS)?}

Zarnegar et al. (2008) developed a prediction model using information readily available, at clinical presentation, which could determine whether patients with APA would have complete resolution of hypertension after adrenalectomy. They used a predictive logistic regression model that was derived using data on 100 patients who underwent adrenalectomy for primary aldosteronism at one tertiary medical center (University of California, San Francisco Medical Center) and was externally validated using an independent series of 67 patients from another center (Mayo Clinic). The variables included age, sex, BMI, size of tumor, family history of hypertension, years of hypertension, number of preoperative antihypertensive medications, plasma potassium (mEq/L), plasma aldosterone (ng/dL), and plasma renin activity (ng/mL/h). Family history of hypertension was defined as one or more first-degree family members with documented hypertension. They concluded that clinical features were similar for patients in the derivation and validation groups. Four readily available predictors ( 2 or fewer antihypertensive medications, body mass index $\leq 25 \mathrm{~kg} / \mathrm{m}^{2}$, duration of hypertension $\leq 6$ years, and female sex) yielded the best predictive model for complete resolution of hypertension after adrenalectomy. Based on the resulting 4-item ARS, 3 likelihood levels for complete resolution were identified: low (0-1), medium (2-3), and high (4-5) with a predictive accuracy of $27 \%$, $46 \%$, and $75 \%$, respectively. The ARS predicts accurately a patient's likelihood of complete resolution of hypertension beyond 1 year (Aronova et al. 2014b).

\section{TREATMENT}

\section{What surgical treatment is recommended for PA?}

Surgical resection is the standard of care for unilateral adrenal adenomas and unilateral adrenal hyper- plasia resulting in primary aldosteronism (Worth et al. 2015).

Open transperitoneal adrenalectomy has been the gold standard of treatment for adrenal disease (Chai et al. 2014). The last years other types of adrenal surgery have evolved and these are; Laparoscopic lateral transperitoneal adrenalectomy (LTA), laparoscopic posterior retroperitoneal adrenalectomy (PRA). LTA has been the standard method for resecting benign adrenal gland tumors. Recently, however, PRA has been more popular as an alternative method (Chai et al. 2014).

Laparoscopic adrenalectomy (LA), has now been proven to be a safe and effective treatment for PA (Shen et al. 1999; Iacobone et al. 2015). Laparoscopically treated patients have fewer postoperative complications and are equally likely to improve in BP and correct hypokalemia, if present preoperatively, when compared with patients treated with open adrenalectomy. Additional benefits of LA are smaller incisions, decreased postoperative pain, and a shorter hospital stay (Takeda et al. 1994; Lee et al. 2008; Iacobone et al. 2015).

In three recent meta-analyses compared the transperitoneal and retroperitoneal adrenalectomy: two concluded that both techniques have equivalent outcomes (Constantinides et al. 2012) whereas the other claimed the retroperitoneal approach to be superior in short-term outcomes (Chen et al. 2013). All these metanalyses studied adrenal surgery in general they were not exclusive to PA.

The indications to laparoscopic unilateral total or partial adrenalectomy in patients with unilateral PA remain controversial (Iacobone et al. 2015).

Conversion to open surgery is required in less than $5 \%$ of cases (Brunt 2006). Perioperative mortality is less than $0.5 \%$, non-fatal complications occur in $5 \%$ to $15 \%$ of cases and most of them are benign (temporary relaxation and/or hypoesthesia of the abdominal wall) (Assalia and Gagner 2004; Brunt 2006; Walz et al. 2006). Fewer than $2 \%$ of patients experience severe complications: hemorrhage requiring transfusion, cardiac or respiratory destabilization (Assalia and Gagner 2004; Brunt 2006; Walz et al. 2006; Steichen et al. 2015).

A modern technique, robot-assisted adrenalectomy (RA) has emerged as an attractive alternative to laparoscopic adrenalectomy (LA), and many studies have shown the feasibility and safety of RA. In the early experience, data suggest that RA, compared with laparoscopic adrenalectomy, may be a safe and feasible option associated with less blood loss and shorter hospital stay when performed by experienced surgeons in selected patients (Tang et al. 2015). 
In a study comparing RA and open adrenalectomy conducted by Probst et al. (2016), they found that RA was safe and cost-effective compared with open adrenalectomy. Increasing experience leads to similar operating times, putting high-volume centers at an advantage (Probst et al. 2016).

\section{How are patients for surgery prepared?}

In the patient scheduled for surgery, both hypertension and hypokalemia should be well controlled preoperatively. Obtaining such control may require a delay in surgery and the addition of an MRA (Funder et al. 2008).

Patients should be treated with a MRA and potassium supplements to lower BP and to correct hypokalemia before surgery. Preoperative MRA for a few weeks before surgery may also decrease the risk of postoperative hypoaldosteronism due to the chronic suppression of aldosterone secretion in the contralateral gland (Steichen et al. 2015). Treatment with spironolactone should be discontinued postoperatively (Young 2003a). Nonetheless, postoperative hyperkalemia is seen in up to $30 \%$ of patients (Fischer et al. 2012; Chiang et al. 2013). This is usually mild and transient, but MRA treatment and potassium supplements should be discontinued at the time of surgery, to minimize the risk, and serum potassium concentrations should be monitored closely, particularly in patients with chronic kidney disease (Chiang et al. 2013).

\section{What is the postoperative management?}

Serum potassium levels should be monitored weekly for 4 weeks. In a small number of patients with APA, marked hyperkalemia develops postoperatively and short-term fludrocortisone supplementation might be required (Mattsson and Young 2006). Because aldosterone production in the contralateral adrenal might be suppressed during the first postoperative weeks, a sodium-rich diet should be recommended (Mattsson and Young 2006).

\section{Is there any risk of kidneys damage or dyslipidemia after adrenalectomy?}

PA patients display relative glomerular hyperfiltration, which is reversed by specific treatment, revealing chronic kidney disease in 30\% of patients. However, further kidney damage is prevented by the treatment of PA (Steichen et al. 2015).

Adrenalectomy can lead to a significant decrease in the GFR, as a consequence of correcting the glomerular hyperfiltration peculiar to PA (TAIPAI Study Group et al. 2009; Wu et al. 2011; Utsumi et al. 2013; Kaga et al. 2015). Furthermore, it is well known that the progression of renal insufficiency eventually causes cardiometabolic events, such as dyslipidemia and premature atherosclerosis (Vaziri 2006; Piecha et al. 2009; Bagrodia et al. 2014; Kaga et al. 2015).

Kaga et al. (2015), from Japan, conducted a study to explore the postoperative changes in serum lipid levels and to identify risk factors associated with postoperative new-onset dyslipidemia in PA patients. They found that a significant decrease in eGFR (estimated GFR) and deterioration of serum lipid levels was identified postoperatively in most patients in their study. Multivariate analysis identified preoperative lower eGFR and higher body mass index as independent predictors for new onset dyslipidemia after surgery. On univariate analyses, additional factors associated with new onset dyslipidemia included older age, male sex, higher LDL-cholesterol, and higher LDL/HDL ratio. They concluded that PA patients had a higher risk of postoperative new-onset or progressive dyslipidemia. Clinicians should pay attention to not only follow-up of renal impairment but also total management of new-onset metabolic events associated with renal insufficiency in PA patients.

\section{Whom to treat and which are the pharmaceutical treatments?}

Patients with IHA, and those with APA or unilateral hyperplasia who are not candidates for or who decline surgery, should receive a MRA (Mattsson and Young 2006).

The goals of treatment are the normalization of serum potassium concentration, blood pressure control and prevention of the direct effects of excess aldosterone on target organs. The non-surgical treatment of PA is based on MRA and dietary sodium restriction.

Two drugs of this class are currently available: spironolactone and eplerenone. The guidelines recommend spironolactone as the primary agent for the management of PA, with eplerenone as an alternative (Funder et al. 2008). Potassium canrenoate and/or canrenone (a metabolite of spironolactone) may also be used (Iacobone et al. 2015).

Spironolactone can, however, be of limited value because of its affinity for androgen and progesterone receptors. This affinity can induce adverse effects such as gynecomastia and sexual dysfunction in men, and menstrual irregularities in women. Gynecomastia was reported in $6.9 \%$ of men who received 
$50 \mathrm{mg}$ of spironolactone daily and in $52.0 \%$ of those who received $150 \mathrm{mg}$ daily (Jeunemaitre et al. 1987; Mattsson and Young 2006).

With change in the molecule of spironolactone, eplerenone was created. The affinity of eplerenone for progestin and androgen receptors is as much as 500 -fold lower than that of spironolactone, thus nullifying the adverse effects associated with progesterone agonism and androgen antagonism. Eplerenone has no active metabolites and a shorter half-life than spironolactone. These characteristics probably underlie the reduced risk of hyperkalemia associated with eplerenone (Sica 2005; Mattsson and Young 2006).

Spironolactone is rapidly metabolized in the liver into a number of metabolites including 7a-methylspironolactone and canrenone (Amar et al. 2015). Potassium canrenoate, is a water-soluble derivative of spironolactone, sharing the same active metabolite canrenone, but probably has a different pattern of metabolism that avoids the formation of intermediate products with anti-androgenic effects (Armanini et al. 1985; Dupont 1985). Where it is available, canrenone (an active metabolite of spironolactone) or potassium canrenoate, its open E-ring water-soluble congener, might be considered, in that they possibly have fewer sex steroid-related side effects. In addition, a small dose of a thiazide diuretic, triamterene, or amiloride can be added to attempt to avoid a higher dose of spironolactone, which may cause side effects (Funder et al. 2008).

From a health economics perspective, however, spironolactone is recommended as first-line drug; the average wholesale price, in USA, for a year of eplerenone therapy (50 $\mathrm{mg}$ twice daily) is US $\$ 2,759$ compared with $\$ 603$ for spironolactone (50 mg twice daily) (Fleming 2005; Mattsson and Young 2006).

Epithelial sodium channel $(\mathrm{ENaC})$ blockers are used when MRA are not well tolerated; thiazide diuretics and calcium channel blockers are used when blood pressure control is insufficient with the first-line treatment (Steichen et al. 2015). Dietary sodium restriction should be implemented in all cases, because the deleterious consequences of hyperaldosteronism are dependent on salt loading (Steichen et al. 2015).

Amiloride is an ENaC blocker that opposes the reabsorption of sodium in exchange for potassium in the distal tubules and collecting ducts. In most countries, it is available in the form of $5 \mathrm{mg}$ tablets, although the usual daily dose required to correct hyperaldosteronism effectively is 10 to $40 \mathrm{mg}$ (Ramsay et al. 1980; Steichen et al. 2015). Another alternative is triamterene.
FH type 1 or glucocorticoid-remediable aldosteronism (GRA) are treated with low-dose dexamethasone $(0.125$ to $0.25 \mathrm{mg} /$ day) or low-dose prednisone ( 2.5 to $5 \mathrm{mg} /$ day) at bedtime efficiently suppresses ACTH secretion, thereby decreasing the ACTHdependent hyperaldosteronism (Litchfield et al. 1998). As glucocorticoid treatment does not always result in normalization of blood pressure, the addition of a MRA should be considered (Mattsson and Young 2006).

\section{What is better, surgery or pharmaceutical treatment?}

Several studies comparing the results of surgery and MRA have reported no differences in terms of blood pressure, serum potassium concentration or cardiovascular and renal outcomes, although the benefits of treatment tend to be observed sooner with surgery (Steichen et al. 2015).

\section{Conclusions}

PA is the major cause of the secondary hypertension. Its prevalence can reach up to $24 \%$ in high risk populations. PA should be searched in patients with high $\mathrm{BP}$ (>160 mmHg systolic or $100 \mathrm{mmHg}$ diastolic), in drug resistant $\mathrm{HTN}$, in patients with HTN and hypokalemia, in first degree relatives of PA patients and in patients with cerebrovascular accidents in $<40$ years old. The gold standard for diagnosing PA is the ARR. If positive we proceed with one of the four confirmatory tests. If one of these is positive then we proceed with localization techniques, AVS and CT scan. If the lesion is unilateral and the patient agrees and is fit for surgery we proceed to excise the lesion. Patients should be treated with a MRA and potassium supplements to lower BP and to correct hypokalemia before surgery. If the lesion is bilateral, we treat with a MRA. We start with spironolactone which is cheaper and if complications appear, substitute with eplerenone. If the MRA is not effective to control BP or are not tolerated, we can use ENaC blocker. If BP control cannot be achieved we can add thiazide diuretics and or calcium channel blockers. Dietary sodium restriction should be implemented in all cases. Laparoscopic adrenalectomy is the operation of choice.

\section{Acknowledgement}

This research did not receive any specific grant from any funding agency in the public, commercial or not-for-profit sector. 


\section{References}

AAES, T.A.A.o.E.S. Primary hyperaldosteronism (Conn's syndrome or aldosterone-producing adrenal tumor). Patient Education. 2016.

Agharazii M, Douville P, Grose JH, Lebel M. Captopril suppression versus salt loading in confirming primary aldosteronism. Hypertension 37, 1440-1443, 2001.

Ahmed AH, Gordon RD, Sukor N, Pimenta E, Stowasser M. Quality of life in patients with bilateral primary aldosteronism before and during treatment with spironolactone and/or amiloride, including a comparison with our previously published results in those with unilateral disease treated surgically. J Clin Endocrinol Metab 96, 2904-2911, 2011.

Al-Salameh A, Cohen R, Desailloud R. Overview of the genetic determinants of primary aldosteronism. Appl Clin Genet 7, 67-79, 2014.

Amar L, Lorthioir A, Azizi M, Plouin PF. Progress in primary aldosteronism. Mineralocorticoid antagonist treatment for aldosterone-producing adenoma. Eur J Endocrinol 172, R125-R129, 2015.

Armanini D, Karbowiak I, Goi A, Mantero F, Funder JW. In-vivo metabolites of spironolactone and potassium canrenoate: determination of potential anti-androgenic activity by a mouse kidney cytosol receptor assay. Clin Endocrinol (Oxf) 23, 341-347, 1985.

Aronova A, Fahey TJ, Zarnegar R Management of hypertension in primary aldosteronism. World J Cardiol 6, 227233, 2014a.

Aronova A, Gordon BL, Finnerty BM, Zarnegar R, Fahey TJ 3rd. Aldosteronoma resolution score predicts long-term resolution of hypertension. Surgery 156, 1387-1393, 2014b.

Assalia A, Gagner M. Laparoscopic adrenalectomy. Br J Surg 91, 1259-1274, 2004.

Bagrodia A, Kopp RP, Mehrazin R, Lee HJ, Liss MA, Jabaji R, Kane CJ, Wake RW, Patterson AL, Wan JY, Derweesh IH. Impact of renal surgery for cortical neoplasms on lipid metabolism. BJU Int 114, 837-843, 2014.

Bergstrom M, Juhlin C, Bonasera TA, Sundin A, Rastad J, Akerstrom G, Langstrom B. PET imaging of adrenal cortical tumors with the 11beta-hydroxylase tracer 11C-metomidate. J Nucl Med 41, 275-282, 2000.

Boland GW, Dwamena BA, Jagtiani Sangwaiya M, Goehler AG, Blake MA, Hahn PF, Scott JA, Kalra MK. Characterization of adrenal masses by using FDG PET: a systematic review and meta-analysis of diagnostic test performance. Radiology 259, 117-126, 2011.

Brown NJ. Aldosterone and end-organ damage. Curr Opin Nephrol Hypertens 14, 235-241, 2005.

Brown MJ. Primary Aldosteronism: the spectre of cure. Clin Endocrinol (Oxf) 82, 785-788, 2015.

Brunt LM. Minimal access adrenal surgery. Surg Endosc 20, 351-361, 2006.

Brunt LM, Moley JF. Adrenal incidentaloma. World J Surg 25, 905-913, 2001.

Burton TJ, Mackenzie IS, Balan K, Koo B, Bird N, Soloviev DV, Azizan EA, Aigbirhio F, Gurnell M, Brown MJ. Evaluation of the sensitivity and specificity of 11C-metomidate positron emission tomography (PET)-CT for lateralizing aldosterone secretion by Conn's adenomas. J Clin Endocrinol Metab 97, 100-109, 2012.

Chai YJ, Kwon H, Yu HW, Kim SJ, Choi JY, Lee KE, Youn YK. Systematic review of surgical approaches for adrenal tumors: lateral transperitoneal versus posterior retroperitoneal and laparoscopic versus robotic adrenalectomy. Int J Endocrinol 2014, 918346, 2014.

Chao CT, Wu VC, Kuo CC, Lin YH, Chang CC, Chueh SJ, Wu KD, Pimenta E, Stowasser M. Diagnosis and management of primary aldosteronism: an updated review. Ann Med 45, 375-383, 2013.

Chen W, Li F, Chen D, Zhu Y, He C, Du Y, Tan W. Retroperitoneal versus transperitoneal laparoscopic adrenalectomy in adrenal tumor: a meta-analysis. Surg Laparosc Endosc Percutan Tech 23, 121-127, 2013.

Chiang WF, Cheng CJ, Wu ST, Sun GH, Lin MY, Sung CC, Lin SH. Incidence and factors of post-adrenalectomy hyperkalemia in patients with aldosterone producing adenoma. Clin Chim Acta 424, 114-118, 2013.

Conder G, Rendle J, Kidd S, Misra RR. A-Z of Abdominal Radiology, Cambridge University Press, Cambridge, UK, 28-37, 2009.

Conn JW. Presidential address. I. Painting background. II. Primary aldosteronism, a new clinical syndrome. J Lab Clin Med 45, 3-17, 1955.

Constantinides VA, Christakis I, Touska P, Palazzo FF. Systematic review and meta-analysis of retroperitoneoscopic versus laparoscopic adrenalectomy. Br J Surg 99, 1639-1648, 2012.

Ctvrtlik F, Koranda P, Tichy T. Adrenal disease: a clinical update and overview of imaging. A review. Biomed Pap Med Fac Univ Palacky Olomouc Czech Repub 158, 23-34, 2014.

Dunnick NR, Korobkin M. Imaging of adrenal incidentalomas: current status. AJR Am J Roentgenol 179, 559-568, 2002. 
Dupont A. Disappearance of spironolactone-induced gynaecomastia during treatment with potassium canrenoate. Lancet 2, 731, 1985.

Fardella CE, Mosso L, Gomez-Sanchez C, Cortes P, Soto J, Gomez L, Pinto M, Huete A, Oestreicher E, Foradori A, Montero J. Primary hyperaldosteronism in essential hypertensives: prevalence, biochemical profile, and molecular biology. J Clin Endocrinol Metab 85 1863-1867, 2000.

Fischer E, Hanslik G, Pallauf A, Degenhart C, Linsenmaier U, Beuschlein F, Bidlingmaier M, Mussack T, Ladurner R, Hallfeldt K, Quinkler M, Reincke M. Prolonged zona glomerulosa insufficiency causing hyperkalemia in primary aldosteronism after adrenalectomy. J Clin Endocrinol Metab 97, 3965-3973, 2012.

Fischer E, Reuschl S, Quinkler M, Rump LC, Hahner S, Bidlingmaier M, Reincke M; Participants of the German Conn's Registry-Else Kroner-Fresenius-Hyperaldosteronism Registry. Assay characteristics influence the aldosterone to renin ratio as a screening tool for primary aldosteronism: results of the German Conn's registry. Horm Metab Res 45, 526-531, 2013.

Fleming T, ed. 2005 Red Book: Pharmacy’s Fundamental Reference. Montvale NJ: Thomson PDR, 2005.

Funder JW, Carey RM, Fardella C, Gomez-Sanchez CE, Mantero F, Stowasser M, Young WF Jr, Montori VM; Endocrine Society. Case detection, diagnosis, and treatment of patients with primary aldosteronism: an endocrine society clinical practice guideline. J Clin Endocrinol Metab 93, 3266-3281, 2008.

Geller DS, Zhang J, Wisgerhof MV, Shackleton C, Kashgarian M, Lifton RP. A novel form of human mendelian hypertension featuring nonglucocorticoid-remediable aldosteronism. J Clin Endocrinol Metab 93, 3117-3123, 2008.

Giacchetti G, Ronconi V, Lucarelli G, Boscaro M, Mantero F. Analysis of screening and confirmatory tests in the diagnosis of primary aldosteronism: need for a standardized protocol. J Hypertens 24, 737-745, 2006.

Gordon R. Mineralocorticoid hypertension. Lancet 344, 240-243, 1994.

Gordon RD, Stowasser M, TunnyTJ, Klemm SA, Rutherford JC. High incidence of primary aldosteronism in 199 patients referred with hypertension. Clin Exp Pharmacol Physiol 21, 315-318, 1994.

Gordon R. Primary aldosteronism. J Endocrinol Invest 18, 495-511, 1995.

Gordon RD. Diagnostic investigations in primary aldosteronism. In: Zanchetti A (ed.), Clinical Medicine Series on Hypertension. Maidenhead: McGraw-Hill International (UK) Ltd; pp. 101-114, 2001.

Hiramatsu K, Yamada T, Yukimura Y, Komiya I, Ichikawa K, Ishihara M, Nagata H, Izumiyama T. A screening test to identify aldosterone-producing adenoma by measuring plasma renin activity: results in hypertensive patients. Arch Intern Med 141, 1589-1593, 1981.

Hofer M. Kidneys and Adrenal Glands. Ultrasound Teaching Manual Hofer, Matthias, Thieme, 37-50, 1999.

Hood S, Cannon J, Foo R, Brown M. Prevalence of primary hyperaldosteronism assessed by aldosterone/renin ratio and spironolactone testing. Clin Med (Lond) 5, 55-60, 2005.

Iacobone M, Citton M, Viel G, Rossi GP, Nitti D. Approach to the surgical management of primary aldosteronism. Gland Surg 4, 69-81, 2015.

Ilias I, Sahdev A, Reznek RH, Grossman AB, Pacak K. The optimal imaging of adrenal tumours: a comparison of different methods. Endocr Relat Cancer 14, 587-599, 2007.

Jeunemaitre X, Chatellier G, Kreft-Jais C, Charru A, DeVries C, Plouin PF, Corvol P, Menard J. Efficacy and tolerance of spironolactone in essential hypertension. Am J Cardiol 60, 820-825, 1987.

Kaga M, Utsumi T, Tanaka T, Kono T, Nagano H, Kawamura K, Kamiya N, Imamoto T, Nihei N, Naya Y, Suzuki $\mathrm{H}$, Ichikawa T. Risk of new-onset dyslipidemia after laparoscopic adrenalectomy in patients with primary aldosteronism. World J Surg 39, 2935-2940, 2015.

Kahn SL, Angle JF. Adrenal vein sampling. Tech Vasc Interv Radiol 13, 110-125, 2010.

Kem DC, Weinberger MH, Mayes DM, Nugent CA. Saline suppression of plasma aldosterone in hypertension. Arch Intern Med 128, 380-386, 1971.

Kline GA. Primary Aldosteronism: unnecessary complexity in definition and diagnosis as a barrier to wider clinical care. Clin Endocrinol (Oxf) 82, 779-784, 2015.

Kucharz EJ. [Michal Litynski---a forgotten author of the first description on primary hyperaldosteronism]. Pol Arch Med Wewn 117, 57-58, 2007.

Lafferty AR, Torpy DJ, Stowasser M, Taymans SE, Lin JP, Huggard P, Gordon RD, Stratakis CA. A novel genetic locus for low renin hypertension: familial hyperaldosteronism type II maps to chromosome 7 (7p22). J Med Genet 37, 831-835, 2000.

Lee J, El-Tamer M, Schifftner T, Turrentine FE, Henderson WG, Khuri S, Hanks JB, Inabnet WB 3rd. Open and laparoscopic adrenalectomy: analysis of the National Surgical Quality Improvement Program. J Am Coll Surg 206, 953-961, 2008. 
Letavernier E, Peyrard S, Amar L, Zinzindohoue F, Fiquet B, Plouin PF. Blood pressure outcome of adrenalectomy in patients with primary hyperaldosteronism with or without unilateral adenoma. J Hypertens 26, 1816-1823, 2008.

Litchfield WR, Anderson BF, Weiss RJ, Lifton RP, Dluhy RG. Intracranial aneurysm and hemorrhagic stroke in glucocorticoid-remediable aldosteronism. Hypertension 31, 445-450, 1998.

Mantero F, Fallo F, Opocher G, Armanini D, Boscaro M, Scaroni C. Effect of angiotensin II and converting enzyme inhibitor (captopril) on blood pressure, plasma renin activity and aldosterone in primary aldosteronism. Clin Sci (Lond) 61, 289s-293s, 1981.

Mantero F, Terzolo M, Arnaldi G, Osella G, Masini AM, Alì A, Giovagnetti M, Opocher G, Angeli A. A survey on adrenal incidentaloma in Italy. Study Group on Adrenal Tumors of the Italian Society of Endocrinology. J Clin Endocrinol Metab 85, 637-644, 2000.

Mattsson C, Young WF. Primary aldosteronism: diagnostic and treatment strategies. Nat Clin Pract Nephrol 2, 198208, 2006.

McCurley A, Pires PW, Bender SB, Aronovitz M, Zhao MJ, Metzger D, Chambon P, Hill MA, Dorrance AM, Mendelsohn ME, Jaffe IZ. Direct regulation of blood pressure by smooth muscle cell mineralocorticoid receptors. Nat Med 18, 1429-1433, 2012.

McKenna TJ, Sequeira SJ, Heffernan A, Chambers J, Cunningham S. Diagnosis under random conditions of all disorders of the renin-angiotensin-aldosterone axis, including primary hyperaldosteronism. J Clin Endocrinol Metab 73, 952-957, 1991.

Melby JC, Spark RF, Dale SL, Egdahl RH, Kahn PC. Diagnosis and localization of aldosterone-producing adenomas by adrenal-vein catheterization. N Engl J Med 277, 1050-1056, 1967.

Mengozzi G, Rossato D, Bertello C, Garrone C, Milan A, Pagni R, Veglio F, Mulatero P. Rapid cortisol assay during adrenal vein sampling in patients with primary aldosteronism. Clin Chem 53, 1968-1971, 2007.

Milliez P, Girerd X, Plouin PF, Blacher J, Safar ME, Mourad JJ. Evidence for an increased rate of cardiovascular events in patients with primary aldosteronism. J Am Coll Cardiol 45, 1243-1248, 2005.

Monticone S, Hattangady NG, Penton D, Isales CM, Edwards MA, Williams TA, Sterner C, Warth R, Mulatero P, Rainey WE. A novel Y152C KCNJ5 mutation responsible for familial hyperaldosteronism type III. J Clin Endocrinol Metab 98, E1861-E1865, 2013.

Moraitis A, Stratakis C. Adrenocortical causes of hypertension. Int J Hypertens 2011, 624691, 2011.

Mulatero P, Rabbia F, Milan A, Paglieri C, Morello F, Chiandussi L, Veglio F. Drug effects on aldosterone/plasma renin activity ratio in primary aldosteronism. Hypertension 40, 897-902, 2002.

Mulatero P, Stowasser M, Loh KC, Fardella CE, Gordon RD, Mosso L, Gomez-Sanchez CE, Veglio F, Young WF Jr. Increased diagnosis of primary aldosteronism, including surgically correctable forms in centers from five continents. J Clin Endocrinol Metab 89, 1045-1050, 2004.

Mulatero P, Monticone S, Bertello C, Viola A, Tizzani D, Iannaccone A, Crudo V, Burrello J, Milan A, Rabbia F, Veglio F. Long-term cardio- and cerebrovascular events in patients with primary aldosteronism. J Clin Endocrinol Metab 98, 4826-4833, 2013.

Papierska L, Cichocki A, Sankowski AJ, Cwikla JB. Adrenal incidentaloma imaging - the first steps in therapeutic management. Pol J Radiol 78, 47-55, 2013.

Piecha G, Adamczak M, Ritz E. Dyslipidemia in chronic kidney disease. Pol Arch Med Wewn 119, 487-492, 2009.

Powlson AS, Gurnell M, Brown MJ. Nuclear imaging in the diagnosis of primary aldosteronism. Curr Opin Endocrinol Diabetes Obes 22, 150-156, 2015.

Probst KA, Ohlmann CH, Saar M, Siemer S, Stoeckle M, Janssen M. Robot-assisted vs open adrenalectomy: evaluation of cost-effectiveness and peri-operative outcome. BJU Int 118, 952-957, 2016.

Ramsay LE, Hettiarachchi J, Fraser R, Morton JJ. Amiloride, spironolactone, and potassium chloride in thiazidetreated hypertensive patents. Clin Pharmacol Ther 27, 533-543, 1980.

Reincke M, Rump LC, Quinkler M, Hahner S, Diederich S, Lorenz R, Seufert J, Schirpenbach C, Beuschlein F, Bidlingmaier M, Meisinger C, Holle R, Endres S; Participants of German Conn's Registry. Risk factors associated with a low glomerular filtration rate in primary aldosteronism. J Clin Endocrinol Metab 94, 869-875, 2009.

Rossi E, Regolisti G, Negro A, Sani C, Davoli S, Perazzoli F. High prevalence of primary aldosteronism using postcaptopril plasma aldosterone to renin ratio as a screening test among Italian hypertensives. Am J Hypertens 15, 896-902, 2002.

Rossi GP, Bernini G, Caliumi C, Desideri G, Fabris B, Ferri C, Ganzaroli C, Giacchetti G, Letizia C, Maccario M, Mallamaci F, Mannelli M, Mattarello MJ, Moretti A, Palumbo G, Parenti G, Porteri E, Semplicini A, Rizzoni D, Rossi E, Boscaro M, Pessina AC, Mantero F; PAPY Study Investigators. A prospective study of the prevalence of primary aldosteronism in 1,125 hypertensive patients. J Am Coll Cardiol 48, 2293-2300, $2006 \mathrm{a}$. 
Rossi GP, Bernini G, Desideri G, Fabris B, Ferri C, Giacchetti G, Letizia C, Maccario M, Mannelli M, Matterello MJ, Montemurro D, Palumbo G, Rizzoni D, Rossi E, Pessina AC, Mantero F; PAPY Study Participants. Renal damage in primary aldosteronism results of the PAPY study. Hypertension 48, 232-238, $2006 \mathrm{~b}$.

Rossi GP, Ganzaroli C, Miotto D, De Toni R, Palumbo G, Feltrin GP, Mantero F, Pessina AC. Dynamic testing with high-dose adrenocorticotrophic hormone does not improve lateralization of aldosterone oversecretion in primary aldosteronism patients. J Hypertens 24, 371-379, 2006c.

Rossi GP, Belfiore A, Bernini G, Desideri G, Fabris B, Ferri C, Giacchetti G, Letizia C, Maccario M, Mallamaci F, Mannelli M, Palumbo G, Rizzoni D, Rossi E, Agabiti-Rosei E, Pessina AC, Mantero F; Primary Aldosteronism Prevalence in Italy Study Investigators. Comparison of the captopril and the saline infusion test for excluding aldosterone-producing adenoma. Hypertension 50, 424-443, 2007.

Rossi GP, Pitter G, Bernante P, Motta R, Feltrin G, Miotto D. Adrenal vein sampling for primary aldosteronism: the assessment of selectivity and lateralization of aldosterone excess baseline and after adrenocorticotropic hormone (ACTH) stimulation. J Hypertens 26, 989-997, 2008.

Schirpenbach C, Seiler L, Maser-Gluth C, Rudiger F, Nickel C, Beuschlein F, Reincke M. Confirmatory testing in normokalaemic primary aldosteronism: the value of saline infusion test and urinary aldosterone metabolites. Eur J Endocrinol 154, 865-873, 2006.

Schirpenbach C, Reincke M. Primary aldosteronism: current knowledge and controversies in Conn's syndrome. Nat Clin Pract Endocrinol Metab 3, 220-227, 2007.

Schwartz GL, Turner ST. Screening for primary aldosteronism in essential hypertension: diagnostic accuracy of the ratio of plasma aldosterone concentration to plasma renin activity. Clin Chem 51, 386-394, 2005.

Shen WT, Lim RC, Siperstein AE, Clark OH, Schecter WP, Hunt TK, Horn JK, Duh QY. Laparoscopic vs open adrenalectomy for the treatment of primary hyperaldosteronism. Arch Surg 134, 628-632, 1999.

Sica DA. Pharmacokinetics and pharmacodynamics of mineralocorticoid blocking agents and their effects on potassium homeostasis. Heart Fail Rev 10, 23-29, 2005.

So A, Duffy DL, Gordon RD, Jeske YW, Lin-Su K, New MI, Stowasser M. Familial hyperaldosteronism type II is linked to the chromosome 7p22 region but also shows predicted heterogeneity. J Hypertens 23, 1477-1484, 2005.

Spyridonidis TJ, Apostolopoulos DJ. Is there a role for Nuclear Medicine in diagnosis and management of patients with primary aldosteronism? Hell J Nucl Med 16, 134-139, 2013.

Steichen O, Lorthioir A, Zinzindohoue F, Plouin PF, Amar L. Outcomes of drug-based and surgical treatments for primary aldosteronism. Adv Chronic Kidney Dis 22, 196-203, 2015.

Stowasser M, Gordon RD, Gunasekera TG, Cowley DC, Ward G, Archibald C, Smithers BM. High rate of detection of primary aldosteronism, including surgically treatable forms, after a "non-selective" screening of hypertensive patients. J Hypertens 21, 2149-2157, 2003.

Stowasser M, Gordon RD. Primary aldosteronism--careful investigation is essential and rewarding. Mol Cell Endocrinol 217, 33-39, 2004.

Stowasser M, Sharman J, Leano R, Gordon RD, Ward G, Cowley D, Marwick TH. Evidence for abnormal left ventricular structure and function in normotensive individuals with familial hyperaldosteronism type I. J Clin Endocrinol Metab 90, 5070-5076, 2005.

Stowasser M, Ahmed A, Pimenta E, Taylor PJ, Gordon RD. Factors affecting the aldosterone/renin ratio. Horm Metab Res 44, 170-176, 2012.

Szolar DH, Korobkin M, Reittner P, Berghold A, Bauernhofer T, Trummer H, Schoellnast H, Preidler KW, Samonigg H. Adrenocortical carcinomas and adrenal pheochromocytomas: mass and enhancement loss evaluation at delayed contrast-enhanced CT. Radiology 234, 479-485, 2005.

TAIPAI Study Group, Wu VC, Chueh SC, Chang HW, Lin LY, Liu KL, Lin YH, Ho YL, Lin WC, Wang SM, Huang KH, Hung KY, Kao TW, Lin SL, Yen RF, Chen YM, Hsieh BS, Wu KD. Association of kidney function with residual hypertension after treatment of aldosterone-producing adenoma. Am J Kidney Dis 54, 665-673, 2009.

Takeda M, Go H, Imai T, Nishiyama T, Morishita H. Laparoscopic adrenalectomy for primary aldosteronism: report of initial ten cases. Surgery 115, 621-625, 1994.

Tang K, Li H, Xia D, Yu G, Guo X, Guan W, Xu H, Ye Z. Robot-assisted versus laparoscopic adrenalectomy: a systematic review and meta-analysis. J Laparoendosc Adv Surg Tech A 25, 187-195, 2015.

Thompson GB, Young WF Jr. Adrenal incidentaloma. Curr Opin Oncol 15, 84-90, 2003.

Tomaschitz A, Pilz S. Aldosterone to renin ratio--a reliable screening tool for primary aldosteronism? Horm Metab Res 42, 382-391, 2010. 
Utsumi T, Kawamura K, Imamoto T, Nagano H, Tanaka T, Kamiya N, Nihei N, Naya Y, Suzuki H, Ichikawa T. Preoperative masked renal damage in Japanese patients with primary aldosteronism: identification of predictors for chronic kidney disease manifested after adrenalectomy. Int J Urol 20, 685-691, 2013.

Vaziri N. Dyslipidemia of chronic renal failure: the nature, mechanisms, and potential consequences. Am J Physiol Renal Physiol 290, F262-F272, 2006.

Walz MK, Alesina PF, Wenger FA, Deligiannis A, Szuczik E, Petersenn S, Ommer A, Groeben H, Peitgen K, Janssen OE, Philipp T, Neumann HP, Schmid KW, Mann K. Posterior retroperitoneoscopic adrenalectomy--results of 560 procedures in 520 patients. Surgery 140, 943-950, 2006.

Weiner ID. Endocrine and hypertensive disorders of potassium regulation: primary aldosteronism. Semin Nephrol 33, 265-276, 2013.

White ML, Gauger PG, Doherty GM, Cho KJ, Thompson NW, Hammer GD, Miller BS. The role of radiologic studies in the evaluation and management of primary hyperaldosteronism. Surgery 144, 926-933, 2008.

Worth PJ, Kunio NR, Siegfried I, Sheppard BC, Gilbert EW. Characteristics predicting clinical improvement and cure following laparoscopic adrenalectomy for primary aldosteronism in a large cohort. Am J Surg 210, 702-709, 2015.

Wu VC, Yang SY, Lin JW, Cheng BW, Kuo CC, Tsai CT, Chu TS, Huang KH, Wang SM, Lin YH, Chiang CK, Chang HW, Lin CY, Lin LY, Chiu JS, Hu FC, Chueh SC, Ho YL, Liu KL, Lin SL, Yen RF, Wu KD; TAIPAI Study Group. Kidney impairment in primary aldosteronism. Clin Chim Acta 412, 1319-1325, 2011.

Young WF Jr. Primary aldosteronism: management issues. Ann N Y Acad Sci 970, 61-76, 2002.

Young WF Jr. Minireview: primary aldosteronism--changing concepts in diagnosis and treatment. Endocrinology 144, 2208-2213, 2003a.

Young WF Jr. Adrenalectomy for primary aldosteronism; authors' reply. Ann Intern Med 138, 157-159, 2003 b.

Young WF, Stanson AW, Thompson GB, Grant CS, Farley DR, van Heerden JA. Role for adrenal venous sampling in primary aldosteronism. Surgery 136, 1227-1235, 2004.

Young WF Jr. Clinical practice. The incidentally discovered adrenal mass. N Engl J Med 356, 601-610, 2007.

Young WF, Stanson AW. What are the keys to successful adrenal venous sampling (AVS) in patients with primary aldosteronism? Clin Endocrinol (Oxf) 70, 14-17, 2009.

Zarnegar R, Young WF Jr, Lee J, Sweet MP, Kebebew E, Farley DR, Thompson GB, Grant CS, Clark OH, Duh QY. The aldosteronoma resolution score: predicting complete resolution of hypertension after adrenalectomy for aldosteronoma. Ann Surg 247, 511-518, 2008. 